\title{
The Relation Between Thyroid Stimulating Hormone and Left Ventricular Strain Parameters in Patients with Subclinical Hypothyroidism
}

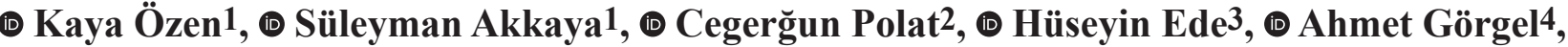 (1) Önder Öztürk1}

${ }_{1}^{1}$ Diyarbakır Gazi Yaşargil Training and Research Hospital, Clinic of Cardiology, Diyarbakır, Turkey

${ }^{2}$ Memorial Dicle Hospital, Clinic of Cardiology, Diyarbakır, Turkey

${ }^{3}$ Hamad Medical Corporation Heart Hospital, Clinic of Cardiology, Doha, Qatar

${ }^{4}$ Diyarbakır Gazi Yaşargil Training and Research Hospital, Clinic of Endocrinology and Metabolism Department, Diyarbakır, Turkey

\begin{abstract}
Objectives: In this study, it was aimed to evaluate the relationship between serum thyroid stimulating hormone (TSH) level and left ventricular strain parameters measured by the two-dimensional speckle tracking imaging among adults with subclinical hypothyroidism (SH).

Materials and Methods: Forty patients with SH were divided into two groups according to TSH level (the first group: TSH values of 4.2-10.0 mIU/L; the second group: TSH values $>10 \mathrm{mIU} / \mathrm{L}$ ). Besides, 20 (control group) ageand gender-matched healthy subjects were included in the

study as the control group. Standard echocardiographic measurements and the two-dimensional speckle tracking imaging measurements of apical two and four cavities, systolic peak longitudinal strain (PLS) from shortaxis images, peak circumferential strain (PCS), global longitudinal strain and global circumferential strain were obtained.

Results: Twenty patients were included in each group. In two-dimensional speckle tracking, PLS in the twodimensional speckle tracking imaging was shown to
\end{abstract}

Address for Correspondence: Hüseyin Ede, HMC Heart Hospital, Clinic of Cardiology, Doha, Qatar

e-mail: huseyinede@gmail.com ORCID: orcid.org/0000-0003-1218-257X

Received: 21.07.2020 Accepted: 14.08.2020

Cite this article as: Özen K, Akkaya S, Polat C, Ede H, Görgel A, Öztürk Ö. The Relation Between Thyroid Stimulating Hormone and Left Ventricular Strain Parameters in Patients with Subclinical Hypothyroidism. EJCM 2020;8(3):123-130.

DOI: 10.32596/ejcm.galenos.2020.07.037

Presented in: The study was presented by Dr. Kaya Özen as a Cardiology Graduation Thesis and was accepted at Diyarbakır Gazi Yaşargil Training and Research Hospital in 2015. In addition, the summary of the study was presented as an oral presentation at the 14th International Congress of Updates in Cardiology and Cardiovascular Surgery held in Antalya on April 5-8, 2018. 


\begin{abstract}
be significantly lower $(\mathrm{p}<0.001)$ in the second group $(-18.76 \pm 1.22 \%)$ compared to the first $(-20.94 \pm 1.87 \%)$ and control group $(-22.18 \pm 2.02 \%)$ patients. PCS value was found to be significantly lower $(\mathrm{p}<0.001)$ in the patients with SH $(-22.63 \pm 1.74 \%$ for the first group, $-22.23 \pm 1.21 \%$ for the second group) compared to the control group $(-24.24 \pm 1.59 \%)$.
\end{abstract}

\section{Introduction}

Subclinical hypothyroidism ( $\mathrm{SH}$ ) is a condition characterized by high thyroid stimulating hormone (TSH) level with normal serum free thyroxine (fT4) level ${ }^{(1)}$. Both hyperthyroidism and hypothyroidism cause changes in cardiac contractility, oxygen consumption of the myocardium, stroke volume of the heart, blood pressure and systemic vascular resistance ${ }^{(2)}$. Many studies in adults have shown that $\mathrm{SH}$ leads to dyslipidemia by change in lipid metabolism and serum cholesterol levels increase in parallel with serum TSH levels ${ }^{(3,4)}$. In addition, it has been shown that the patients with SH may have increased risk to develop atherosclerosis, coronary heart disease, and high risk of myocardial infarction ${ }^{(2,5)}$. Myocardial tissue contains plenty of thyroid hormone receptors and they are very sensitive to thyroid hormones. Hypothyroidism may affect myocardial function by decreasing the activity of enzymes that play a role in the intracellular calcium cycle and it regulates diastolic function by modifying contractile protein expression ${ }^{(2)}$. Thyroid hormone deficiency leads to decrease in myocardial contraction, cardiac output and heart rate and leads to increase in systemic vascular resistance. All these changes increase the tendency to develop heart failure ${ }^{(6)}$.

In patients with $\mathrm{SH}$, there is an impairment of left ventricular systolic and diastolic functions, although not as pronounced as obvious hypothyroidism. In studies conducted with a small number of patients, cardiac dysfunctions observed in $\mathrm{SH}$ have been shown to be
Conclusion: In this study, the left ventricle (LV) functions in patients with SH were evaluated by conventional and advanced echocardiographic techniques, and subclinical impairment was found in LV functions as TSH level increased.

Keywords: Subclinical hypothyroidism, echocardiography, speckle tracking, strain

reversible with L-thyroxine treatment ${ }^{(7,8)}$. In a large-scale study among adults, it was shown that the risk of heart failure in patients with TSH value of $\geq 10 \mathrm{mIU} / \mathrm{L}$ was moderately increased, whereas this risk was found to be same among patients with TSH value between 4.5 and 9.9 $\mathrm{mIU} / \mathrm{L}$ compared to the normal population ${ }^{(9)}$.

In this study, it was aimed to evaluate the relationship between serum TSH level and left ventricular strain parameters measured by two-dimensional speckle tracking method among the patients with $\mathrm{SH}$.

\section{Materials and Methods}

In this prospective study, patients between 18 and 55 years of age were consecutively included between January 1, 2014 and December 31, 2014. The patients who had diabetes mellitus (DM), any malignancy, liver disease (serum transaminase level is more than twice the upper limit), kidney disease (serum creatinine value above 1.2 $\mathrm{mg} / \mathrm{dL}$ ), presence of active infection, arterial hypertension (the patients with history of antihypertensive drug use or blood pressure measurement 140/90 $\mathrm{mmHg}$ in the last six months), and pulmonary hypertension (those with mean pulmonary artery systolic pressure $>30 \mathrm{mmHg}$ ), any patients with moderate or severe valve disease, coronary artery disease, atrial fibrillation, left ventricular ejection fraction $(\mathrm{EF})<50 \%$ or congestive heart failure (those with a functional capacity of New York Heart Association "NYHA" II and above), and users of any drugs affecting thyroid or heart function, or those with a body mass index 
(BMI) more than $31 \mathrm{~kg} / \mathrm{m}^{2}$ were not included in the study. Patients with a fT4 value below the reference range (0.7$1.8 \mathrm{ng} / \mathrm{dL}$ ) were not included in the study.

Detailed physical examination of each case was performed, blood pressures, weight and height were measured. BMI was calculated by dividing body weight $(\mathrm{kg})$ by the height (square meter) square. Systolic and diastolic blood pressures were measured in the supine position by a sphygmomanometer from the right arm, after at least 10 minutes of rest. All blood samples (lipid levels and thyroid function tests) were taken at the morning following a 12-hour night fast. Triglyceride and total cholesterol were measured enzymatically by DP modular system (Roche Diagnostic Corp., Indianapolis, IN). Thyroid hormone parameters were evaluated by electrochemiluminescence immunoassay method using Cobas 8000 modular analyser series immunochemistry module (cobas e602) device. SH was defined as high TSH level $(>4.20 \mathrm{mIU} / \mathrm{L}$ ) and normal fT4 (reference range 0.7-1.8 ng/dL) according to laboratory reference. Patients were divided into three groups according to thyroid function values: the first group (those with TSH level 4.2$10 \mathrm{mIU} / \mathrm{L}$ ), the second group (those with TSH level $>10$ $\mathrm{mIU} / \mathrm{L}$ ), and the control group [those with normal TSH, fT4 and free triiodothyronine (fT3) levels].

Echocardiographic measurements were made in the supine position, $30^{\circ}$ to the left side, with harmonic Philips Epiq 7C device with a $2.5 \mathrm{MHz}$ transducer in accordance with the current manual of American Society of Echocardiography. The examinations were made by a single investigator and in the middle of the day to eliminate the effect of circadian changes on diastolic dysfunction ${ }^{(10)}$. Teichholz method was used for left ventricular $\mathrm{EF}^{(10)}$. Tissue Doppler measurements were obtained by applying pulsed wave tissue Doppler to the basal segments of the left ventricle's lateral wall and interventricular septum in four apical cavity windows. In each case, three heartbeat measurements were made one after another for all positions, and the mean values obtained were used for statistical analysis.
At the end of expirium, two-dimensional gray-scale (frame rate: $40-80 / \mathrm{sec}$ ) apical two-, three- and fourchamber images; basal, mid, and apical images of short axes images were evaluated for speckle tracking strain examination. Images were evaluated offline with QLAB V6.0 (Advanced Quantification Software version; Philips) program. On the apical two-, three- and four-chamber images, the endocardial borders of the mitral annulus and the apex in endocardial border were marked and automatic trace follow-up was performed. Endocardial borders were again observed in the end-systolic frame. Afterwards, the images were animated, and traces were confirmed. Areas that could not be tracked were excluded. The peak systolic strain was measured and the global longitudinal strain (GLS) was centered to evaluate myocardial function. After that, endocardial boundaries were determined through software by marking anatomical structures from recorded circumferential strain short axis basal, mid, and apical images, manual anterior, inferior, and interventricular parts. Afterwards, images were animated, and traces were confirmed in end-systolic frame.

The clinical and echocardiographic values of the groups were compared. The study protocol was approved by the local ethics committee (approval no: 2015/341). The informed consents of all subjects were obtained in a written format.

\section{Statistical Analysis}

Version 12 IBM SPSS analysis program (IBM Corp. Armonk, NY, USA) for Windows was used for statistical analysis. The suitability of the data to normal distribution was evaluated by using the Kolmogorov-Smirnov test. Descriptive variables were mean \pm standard deviation for normally distributed continuous variables, median (interquartile difference) for non-normally distributed continuous variables; expressed as a number (percent) for categorical variables. One-way ANOVA test was used in parametric variables, which showed normal distribution in comparing the average among the groups and "Tukey honestly significant difference" test was employed in determining the group causing the difference; the Kruskal- 
Wallis test was used in nonparametric variables that did not show normal distribution, and the Mann-Whitney $\mathrm{U}$ test was used to determine the group that caused the difference. The chi-square test was used to evaluate the relationship among categorical variables. The direction of the relationship among the groups was examined with the Spearman correlation test. In the analyses, $\mathrm{p}<0.05$ value was considered significant.

\section{Results}

A total of 60 patients were included in the study. There was no difference among the groups in terms of age, BMI, and triglyceride. Clinical and laboratory findings of the groups are shown in Table 1.

Left ventricular diameters, wall thicknesses and left ventricular EFs were similar in all three groups. It was observed that tissue Doppler parameters were preserved in patients with $\mathrm{SH}$. The transmitral early/late (E/A) ratio decreased significantly in the second group compared to the other two groups. There was no significant difference among the groups in respect to the mitral velocity/mitral flow (E/E') ratio, although it was found to be higher in the second group compared to the control group. Echocardiographic data of the groups are shown in Table 2.

In the two-dimensional speckle tracking analysis, the left ventricular systolic longitudinal functions were shown to decrease significantly both in the second group and in the first group compared to the control group (Table 3). In the evaluation of the peak systolic longitudinal (PSL) function, a significant decrease was observed in the PSL values of the patients in the second group compared to the first group but there was no significant difference in respect to the global systolic longitudinal functions (Table 4). With the same technique, the left ventricular systolic circumferential functions decreased significantly in the first group and second group compared to the control group, but there was no significant difference between the first group and the second group (Table 3).

Table 1. The comparison of the groups in respect to demographic and laboratory data

\begin{tabular}{|c|c|c|c|c|c|}
\hline & $\begin{array}{l}\text { First group } \\
(n=20)\end{array}$ & $\begin{array}{l}\text { Second group } \\
(n=20)\end{array}$ & $\begin{array}{l}\text { Control group } \\
(n=20)\end{array}$ & $p^{a}$ & $\mathbf{p}^{\mathbf{b}}$ \\
\hline Age (year) & $37.5 \pm 5.0$ & $40.1 \pm 9.4$ & $34.8 \pm 6.4$ & 0.08 & - \\
\hline Gender, male, $n(\%)$ & $3(15)$ & $3(15)$ & $3(15)$ & 1 & - \\
\hline TSH (mIU/L) & $6.0(5.6-7.1)$ & $14.7(11.6-21.4)$ & $3.7(2.3-4.1)$ & $<0.001$ & $\begin{array}{l}\text { For G1 - G2; } p<0.001 \\
\text { For G1 - G3; } p<0.01 \\
\text { For G2 - G3; }<0.001\end{array}$ \\
\hline fT4 (ng/dL) & $1.09(0.98-1.25)$ & $1.04(0.96-1.24)$ & $1.11(1.03-1.25)$ & 0.50 & - \\
\hline fT3 (ng/dL) & $3.3 \pm 0.5$ & $2.8 \pm 0.4$ & $3.2 \pm 0.5$ & $<0.05$ & $\begin{array}{l}\text { For G1 - G2; } p<0.05 \\
\text { For G1 - G3; } p=0.77 \\
\text { For G2 - G3; } p=0.08\end{array}$ \\
\hline BMI $\left(\mathrm{kg} / \mathrm{m}^{2}\right)$ & $24.8 \pm 3.4$ & $25.4 \pm 4.1$ & $23.9 \pm 2.8$ & 0.40 & - \\
\hline Systolic blood pressure $(\mathrm{mmHg})$ & $114 \pm 13$ & $122 \pm 18$ & $109 \pm 13$ & $<0.05$ & $\begin{array}{l}\text { For G1 - G2; } p=0.18 \\
\text { For G1 - G3; } p=0.59 \\
\text { For G2 - G3; } p<0.05\end{array}$ \\
\hline Diastolic blood pressure (mmHg) & $72 \pm 11$ & $80 \pm 11$ & $68 \pm 11$ & $<0.01$ & $\begin{array}{l}\text { For G1 - } G 2 ; p=0.10 \\
\text { For G1 - G3; } p=0.43 \\
\text { For G2 - G3; } p<0.005\end{array}$ \\
\hline Triglyceride (mg/dL) & $128.1 \pm 53.5$ & $133.6 \pm 86.1$ & $108.6 \pm 42.3$ & 0.40 & - \\
\hline Total cholesterol (mg/dL) & $174.8 \pm 52.3$ & $177.1 \pm 28.7$ & $147.8 \pm 32.4$ & 0.051 & - \\
\hline
\end{tabular}


In the correlation analysis, it was found that TSH level was correlated with the total cholesterol $(r=0.37$; $\mathrm{p}<0.005)$, E/E' ratio $(\mathrm{r}=0.26 ; \mathrm{p}<0.05)$, peak longitudinal strain (PLS) $(\mathrm{r}=0.62 ; \mathrm{p}<0.001)$ peak circumferential strain (PCS) $(r=0.45 ; \mathrm{p}<0.001)$, GLS $(\mathrm{r}=0.61 ; \mathrm{p}<0.001)$, global circumferential strain $(\mathrm{GCS})(\mathrm{r}=0.41 ; \mathrm{p}<0.001)$. No relationship was detected between TSH level and age, BMI, systolic blood pressure, left ventricular wall thickness, left atrium, and left ventricular EF.

\section{Discussion}

In our study, left ventricular strain values measured via two-dimensional speckle tracking analysis were observed to be decreased in patients with SH. It was found that the TSH level was correlated with the two-dimensional and threedimensional left ventricle structure with their functions and mechanics in all patients with SH. In previous studies, cardiac re-modelling was observed and there was as a decreased left ventricular diastolic function and preserved

Table 2. The comparison of the groups in respect to echocardiographic measurements

\begin{tabular}{|c|c|c|c|c|}
\hline & $\begin{array}{l}\text { First group } \\
(n=20)\end{array}$ & $\begin{array}{l}\text { Second group } \\
(n=20)\end{array}$ & $\begin{array}{l}\text { Control group } \\
(n=20)\end{array}$ & $\mathbf{p}$ \\
\hline LVEDD (mm) & $44 \pm 4$ & $46 \pm 4$ & $46 \pm 3$ & 0.14 \\
\hline LVESD (mm) & $27 \pm 5$ & $27 \pm 4$ & $28 \pm 4$ & 0.50 \\
\hline IVS (mm) & $8.2 \pm 1.6$ & $8.6 \pm 1.6$ & $7.9 \pm 1.1$ & 0.37 \\
\hline PWD (mm) & $5.9 \pm 1.4$ & $6.2 \pm 0.9$ & $6.2 \pm 1.0$ & 0.64 \\
\hline $\mathrm{LA}(\mathrm{mm})$ & $30.2 \pm 3.8$ & $31.9 \pm 2.5$ & $30.8 \pm 3.0$ & 0.24 \\
\hline Mitral E/A ratio & $1.3(1.1-1.5)$ & $1.3(1.1-1.4)$ & $1.5(1.3-1.8)$ & $<0.01$ \\
\hline E/E' ratio & $6.2 \pm 2.1$ & $5.9 \pm 1.0$ & $5.4 \pm 1.0$ & 0.28 \\
\hline
\end{tabular}

Table 3. The data of the patients related to two-dimensional speckle tracking analyses

\begin{tabular}{|c|c|c|c|c|c|}
\hline & $\begin{array}{l}\text { First group } \\
(n=20)\end{array}$ & $\begin{array}{l}\text { Second group } \\
(n=20)\end{array}$ & $\begin{array}{l}\text { Control group } \\
(n=20)\end{array}$ & $p^{a}$ & $p^{b}$ \\
\hline PLS (\%) & $-20.94 \pm 1.87$ & $-18.76 \pm 1.22$ & $-22.18 \pm 2.02$ & $<0.001$ & $\begin{array}{l}\text { For } G 1-G 2 ; p<0.005 \\
\text { For } G 1-G 3 ; p=0.07 \\
\text { For } G 2 \text { - G3; } p<0.001\end{array}$ \\
\hline PCS (\%) & $-22.63 \pm 1.74$ & $-22.23 \pm 1.21$ & $-24.24 \pm 1.59$ & $<0.001$ & $\begin{array}{l}\text { For } G 1-G 2 ; p=0.68 \\
\text { For } G 1-G 3 ; p<0.01 \\
\text { For } G 2 \text { - } G 3 ; p<0.001\end{array}$ \\
\hline
\end{tabular}

PLS: Peak longitudinal strain, PCS: Peak circumferential strain, G1: The first group, G2: the second group, G3: The control group, $n$ : Number $p^{a}$ : Significance value; $p^{b}: p$ values between the groups

Table 4. The data of the patients related to three-dimensional speckle tracking analyses

\begin{tabular}{|c|c|c|c|c|c|}
\hline & $\begin{array}{l}\text { First group } \\
(n=20)\end{array}$ & $\begin{array}{l}\text { Second group } \\
(n=20)\end{array}$ & $\begin{array}{l}\text { Control group } \\
(n=20)\end{array}$ & $p^{a}$ & $\mathbf{p}^{b}$ \\
\hline GLS (\%) & $-18.9 \pm 1.3$ & $-18.2 \pm 1.17$ & $-20.9 \pm 1.55$ & $<0.001$ & $\begin{array}{l}\text { For } \mathrm{G} 1 \text { - } \mathrm{G} 2 ; \mathrm{p}=0.28 \\
\text { For } \mathrm{G} 1-\mathrm{G} 3 ; \mathrm{p}<0.001 \\
\text { For } \mathrm{G} 2-\mathrm{G} 3 ; \mathrm{p}<0.001\end{array}$ \\
\hline GCS (\%) & $-21.03 \pm 1.5$ & $-21.08 \pm 0.96$ & $-21.5 \pm 1.17$ & $<0.001$ & $\begin{array}{l}\text { For } G 1-G 2 ; p=0.99 \\
\text { For } G 1-G 3 ; p<0.005 \\
\text { For } G 2-G 3 ; p<0.005\end{array}$ \\
\hline
\end{tabular}

GLS: Global longitudinal strain, GCS: Global circumferential strain, G1: The first group, G2: the second group, G3: The control group, n: Number $p^{a}$ : Significance value; $p^{b}: p$ values between the groups 
$\mathrm{EF}$ in patients with $\mathrm{SH}^{(11-13)}$. Further studies indicated that TSH concentration did not have relation with left ventricular (LV) structure in both types, but TSH concentration was found to be related to LV contractility in these studies ${ }^{(14,15)}$. However, most of the analyses are posterior wall (PW) and tissue Doppler parameters, and these parameters cannot completely show early structure and dysfunctions (deformation).

In the studies, new echocardiographic techniques [Two-dimensional Speckle Tracking echocardiography (STE), Three-dimensional Speckle Tracking imaging] have been shown to be useful in showing early myocardial deformations and cardiac remodelling in two different spatial sections ${ }^{(11,16)}$. Conventional parameters derived from tissue Doppler have some shortcomings. These shortcomings (low repeatability, one-sided view of myocardial deformation and regional strain only) have been shown to be less in two-dimensional and threedimensional speckle tracking imaging techniques. This superiority of these techniques contributes to the detailed evaluation of myocardial function ${ }^{(16-18)}$. However, in contrast to radial strain imaging, the correctness and reproducibility of the left ventricular myocardial strain has been shown in longitudinal strain and circumferential strain imaging ${ }^{(17,18)}$. This is very important because left ventricular longitudinal systolic deformation is the risk of cardiovascular disease and is the first parameter that is impaired in patients with preserved LV EF. Left ventricular longitudinal deformation is an important parameter in the studies since it is the first parameter to be impaired in cardiac diseases ${ }^{(17-19)}$. In addition, longitudinal strain is an independent predictor of allcause mortality ${ }^{(19)}$. On the other hand, the compensatory increase of the left ventricular circumferential shortening against longitudinal strain reduction is important for the continuation of left ventricular systolic functions ${ }^{(16,18)}$.

We found that the functions of the two-dimensional left ventricle detected by STE were significantly reduced in patients with SH (group 1 and group 2). In our study, LV global longitudinal function was significantly lower in the patients with SH compared to the normal group. Global longitudinal function, subendocardial longitudinally arranged myocardial fibres, are expression of contraction and its deterioration may tend to ischemia. Decreased global longitudinal function in patients with $\mathrm{SH}$ can impair coronary flow reserve and hence coronary microvascular function, and this may tend to ischemic heart disease. It may explain the tendency to develop coronary events and the increased risk of coronary-related mortality in individuals with SH. It may be possible to explain the disruption of left ventricular mechanics in patients with SH by several mechanisms.

For example, fT4 and fT3 hormones enter the cell through a possible unique transport mechanism and bind to the triiodothyronine receptor in the nucleus. This complex then binds to the thyroid hormone response element of many cell component genes and regulates $\mathrm{Ca}^{2+}$-ATPase, myosin, $\beta$-adrenergic receptors, adenylyl cyclase, guanine nucleotide binding proteins, $\mathrm{Na}^{+} /$ $\mathrm{Ca}^{2+}$ modifier, $\mathrm{Na}^{+} / \mathrm{K}^{+}$-ATPase and the transcription of genes encoding voltage-gated potassium channels in the sarcoplasmic reticulum. Thus, it increases cardiac contractility by causing intracellular $\mathrm{Ca}^{2+}$ increase ${ }^{(20)}$. In the patients with $\mathrm{SH}$, we can explain the result that the cardiac functions are impaired due to the defect in these mechanisms (with the effect on the receptor even if the level of these hormones is within the normal reference range). $\mathrm{SH}$ is associated with some tissue changes (Myocardial fibre compatibility change, capillary redistribution, changes in collagen structure, dehydration $)^{(21,22)}$. Additionally, $\mathrm{SH}$ is associated with left ventricular hypertrophy. This significantly affects left ventricular mechanics ${ }^{(14)}$. Also, decreased cardiac output and increased systemic vascular resistance are the characteristic changes of SH. These may be responsible for decreased cardiac mechanics in this population $^{(22,23)}$. The last and the most important reason is that other cardiovascular risk factors (DM, obesity, dyslipidemia) may accompany $\mathrm{SH}$ to contribute to the disruption of left ventricular mechanics ${ }^{(24)}$. 
Especially two-dimensional longitudinal and circumferential strains were significantly lower in patients with $\mathrm{SH}$ than in the control group. There was no significant difference in other parameters (GLS, PCS, GCS) in the second group and in the first group in terms of PLS, except in the second group compared to the first group. Although thyroid hormones are within the normal reference range in patients with $\mathrm{SH}$, high serum $\mathrm{TSH}$ values may cause down regulation of thyroid hormone receptors at the molecular level. With this effect, left ventricular structure and dysfunction can be explained. The studies have shown that left ventricular systolic and diastolic functions are improved by L-thyroxine treatment, but do not return to normal completely ${ }^{(25,26)}$. This means that the normal TSH level does not mean complete recovery of left ventricular mechanics (especially diastolic function). Although previous studies showed that left ventricular diastolic functions were completely improved after the treatment with conventional (PW, tissue Doppler) parameters, it was observed that left ventricular diastolic functions improved but this did not completely normalize, since more sensitive techniques were used in new studies $^{(25,26)}$.

Our findings were like those obtained by Tadic et al. ${ }^{(27)}$ using tissue Doppler and left ventricular longitudinal strain imaging technique in patients with SH. Abdulrahman et al. ${ }^{(28)}$ examined longitudinal and circumferential left ventricular functions in patients with overt hypothyroidism and showed that these functions were clearly impaired 4 weeks after the discontinuance of L-thyroxine treatment. These findings showed the necessity of using more sensitive techniques. In studies conducted in patients with $\mathrm{SH}$, the measurement of the function and mechanics of the three-dimensional left ventricle was confirmed by two-dimensional speckle tracking findings and additional parameters. Especially three-dimensional longitudinal strain analysis shows myocardial dysfunction. While longitudinal dysfunctions return after treatment, circumferential function does not return completely ${ }^{(28)}$. This makes us think that longitudinal function is impaired and recovered early compared to circumferential function.

In our study, it was observed that stroke volume, endsystole volume, end-diastole volume, as well as cardiac output decreased more among the patients in the second group compared to the patients in the first group and control group. This result suggests that LV dysfunction caused by increased peripheral resistance may be related to TSH level.

Correlation between TSH level and longitudinal strain and circumferential strain was observed in our study. This may indicate a relationship between $\mathrm{SH}$ and left ventricular deformation. These findings may show the relationship of TSH with systolic and global myocardial functions in patients with $\mathrm{SH}$ and possibly may explain the increased cardiovascular morbidity in this population.

The low number of patients, high ratio of females in the groups and the fact that coronary artery disease was not excluded by coronary angiography or other imaging methods reduces the power of the study.

\section{Conclusion}

We found a good correlation between TSH and speckle tracking parameters (PCS, PLS, GCS, GLS) in patients with $\mathrm{SH}$. These findings suggest that the speckle tracking technique is useful in the recognition of circumferential strain disorder and diastolic dysfunction among the patients with $\mathrm{SH}$.

\section{Ethics}

Ethics Committee Approval: The study protocol was approved by the local ethics committee (approval no: 2015/341).

Informed Consent: The informed consents of all subjects were obtained in a written format.

Peer-review: Externally peer-reviewed.

\section{Authorship Contributions}

Surgical and Medical Practices: K.Ö., S.A., C.P., H.E., A.G., Ö.Ö., Concept: K.Ö., Ö.Ö., Design: K.Ö., A.G., Ö.Ö., Data Collection or Processing: K.Ö., S.A., C.P., 
H.E., A.G., Analysis or Interpretation: K.Ö., S.A., C.P., H.E., A.G., Ö.Ö., Literature Search: K.Ö., S.A., C.P., H.E., A.G., Ö.Ö., Writing: K.Ö., S.A., C.P., H.E., A.G., Ö.Ö.

Conflict of Interest: No conflict of interest was declared by the authors.

Financial Disclosure: The authors declared that this study received no financial support.

\section{References}

1. Taylor PN, Razvi S, Pearce SH, Dayan CM. Clinical review: A review of the clinical consequences of variation in thyroid function within the reference range. J Clin Endocrinol Metab 2013;98:3562-71.

2. Danzi S, Klein I. Thyroid disease and the cardiovascular system. Endocrinol Metab Clin North Am 2014;43:517-28

3. Hussain A, Elmahdawi AM, Elzeraidi NE, Nouh F, Algathafi K. The Effects of Dyslipidemia in Subclinical Hypothyroidism. Cureus 2019;11:e6173.

4. Abreu IM, Lau E, de Sousa Pinto B, Carvalho D. Subclinical hypothyroidism: to treat or not to treat, that is the question! A systematic review with metaanalysis on lipid profile. Endocr Connect 2017;6:188-99.

5. Goyal G, Goyal LD, Singla H, Sheenam, Arora K, Kaur H. Subclinical Hypothyroidism and Associated Cardiovascular Risk Factor in Perimenopausal Females. J Midlife Health 2020;11:6-11.

6. Ozturk S, Alcelik A, Ozyasar M, et al. Evaluation of left ventricular systolic asynchrony in patients with subclinical hypothyroidism. Cardiol J 2012;19:374-80.

7. Nakova VV, Krstevska B, Kostovska ES, Vaskova O, Ismail LG. The effect of levothyroxine treatment on left ventricular function in subclinical hypothyroidism. Arch Endocrinol Metab 2018;62:392-8.

8. Rodondi N, Bauer DC, Cappola AR, et al. Subclinical thyroid dysfunction, cardiac function, and the risk of heart failure. The Cardiovascular Health Study. J Am Coll Cardiol 2008;52:1152-9.

9. Franzoni F, Galetta F, Fallahi P, et al. Effect of L-thyroxine treatment on left ventricular function in subclinical hypothyroidism. Biomed Pharmacother 2006;60:431-6

10. Lang RM, Bierig M, Devereux RB, et al. Recommendations for chamber quantification: a report from the American Society of Echocardiography's Guidelines and Standards Committee and the Chamber Quantification Writing Group, developed in conjunction with the European Association of Echocardiography, a branch of the European Society of Cardiology. J Am Soc Echocardiogr 2005;18:1440-63.

11. Vitale G, Galderisi M, Lupoli GA, et al. Left ventricular myocardial impairment in subclinical hypothyroidism assessed by a new ultrasound tool: pulsed tissue Doppler. J Clin Endocrinol Metab 2002;87:4350-5.

12. Arinc H, Gunduz H, Tamer A, et al. Tissue Doppler echocardiography in evaluation of cardiac effects of subclinical hypothyroidism. Int J Cardiovasc Imaging 2006;22:177-86.

13. Mishra TK, Routray SN, Das S, Behera M. Left ventricular dysfunction in patients with subclinical hypothyroidism and its reversibility after hormone therapy. J Assoc Physicians India 2005;53:943-6.
14. Kosar F, Sahin I, Aksoy Y, Uzer E, Turan N. Usefulness of pulsed wave tissue Doppler echocardiography for the assessment of the left and right ventricular function in patients with clinical hypothyroidism. Echocardiography 2006;23:471-7.

15. Pearce EN, Yang Q, Benjamin EJ, Aragam J, Vasan RS. Thyroid function and left ventricular structure and function in the Framingham heart study. Thyroid 2010;20:369-73.

16. Mor-Avi V, Lang RM, Badano LP, et al. Current and evolving echocardiographic techniques for the quantitative evaluation of cardiac mechanics: ASE/EAE consensus statement on methodology and indications endorsed by the Japanese Society of Echocardiography. Eur J Echocardiogr 2011;12:167-205.

17. Perk G, Tunick PA, Kronzon I. Non-Doppler two-dimensional strain imaging by echocardiography-from technical considerations to clinical applications. J Am Soc Echocardiogr 2007;20:234-43.

18. Biswas M, Sudhakar S, Nanda NC, et al. Two- and three-dimensional speckle tracking echocardiography: clinical applications and future directions. Echocardiography 2013;30:88-105.

19. Ersbøll M, Valeur N, Mogensen UM, et al. Prediction of all-cause mortality and heart failure admissions from global left ventricular longitudinal strain in patients with acute myocardial infarction and preserved left ventricular ejection fraction. J Am Coll Cardiol 2013;61:2365-73.

20. LeGrys VA, Funk MJ, Lorenz CE, et al. Subclinical hypothyroidism and risk for incident myocardial infarction among postmenopausal women. J Clin Endocrinol Metab 2013;98:2308-17.

21. Triggiani V, Angelo Giagulli V, De Pergola G, Licchelli B, Guastamacchia E, Iacoviello M. Mechanisms Explaining the Influence of Subclinical Hypothyroidism on the Onset and Progression of Chronic Heart Failure. Endocr Metab Immune Disord Drug Targets 2016;16:2-7.

22. Yao Z, Gao X, Liu M, et al. Diffuse Myocardial Injuries are Present in Subclinical Hypothyroidism: A Clinical Study Using Myocardial T1mapping Quantification. Sci Rep 2018;8:4999.

23. Ripoli A, Pingitore A, Favilli B, et al. Does subclinical hypothyroidism affect cardiac pump performance? Evidence from a magnetic resonance imaging study. J Am Coll Cardiol 2005;45:439-45.

24. Wu J, Tao Y, Gu H, Sui J. Association Between Cardiovascular Risk Factors and Serum Thyrotropin Concentration Among Healthy Chinese Subjects and Subjects with Unsuspected Subclinical Hypothyroidism. Clin Lab 2016;62:807-14.

25. Ilic S, Tadic M, Ivanovic B, Caparevic Z, Trbojevic B, Celic V. Left and Right ventricular structure and function in subclinical hypothyroidism: The Effects of one-year levothyroxine treatment. Med Sci Monit 2013;19:960-8.

26. Yazici M, Gorgulu S, Sertbas Y, et al. Effects of thyroxin therapy on cardiac function in patients with subclinical hypothyroidism: index of myocardial performance in the evaluation of left ventricular function. Int J Cardiol 2004;95:135-43.

27. Tadic M, Ilic S, Kostic N, Caparevic Z, Celic V. Subclinical hypothyroidism and left ventricular mechanics: a three-dimensional speckle tracking study. J Clin Endocrinol Metab 2014;99:307-14.

28. Abdulrahman RM, Delgado V, Hoftijzer HC, et al. Both exogenous subclinical hyperthyroidism and short-term overt hypothyroidism affect myocardial strain in patients with differentiated thyroid carcinoma. Thyroid 2011;21:471-6. 